\title{
PENGARUH KOMODIFIKASI DALAM PENCIPTAAN TARI PADA SANGGAR-SANGGAR DI KOTA MEDAN
}

\author{
NURLITA DEVAYANI \\ Prodi Pendidikan Tari
}

\begin{abstract}
Devayani, Nurlita. 2113142054. The Effect of Commodification on Medan's Dance Studios in Dance Composing. A thesis, Faculty of languages and arts, State University of Medan 2015

Based on the enthusiasm of received the profit as much as possible caused a symptom of commodification appear in every sector of life. Included arts sector, in this case was more spesification in dance arts. Theory that used in this research was the theory of commodification that incuded production, distribution, and consument. Composing theory based on the exploration, improvisation, formation, and development theory in this case was seen based on qualitative and quantitative. The time when the research conducted was in october until november 2015. The place of the research conducted was on Sanggar Ai-ai Dancer at kecamatan Medan Denai and SanggarNusindo at Kecamatan Medan timur.

Commodification affect the quality and quantity of dance movement and also dance performance from Sanggar Ai-ai Dancer and Nusindo. That's all because of the market demands were influenced in the process of dance composing, In result they gave priority to the commercial demands. Then to change the merits became the material, occured the process of production, distribution, and consument to both of the Sanggar.
\end{abstract}

Keywords :Commodifcation Effect, Sanggar Ai-ai dancer, SanggarNusindo 


\section{PENDAHULUAN}

Kota Medan merupakan ibu kota provinsi Sumatera Utara, hal ini didasarkan atas faktor sejarah terbentuknya Kota Medan yang memiliki cikal bakal dari wilayah kekuasaan Kesultanan Deli pada waktu itu. Pada perkembangan lanjutan, cikal Kota Medan sebagai sebentuk wilayah perkotaan memiliki penduduk yang dapat digolongkan pada kategori masyarakat heterogen, yaitu masyarakat yang terdiri dari berbagai jenis suku, agama, ras dan golongan. Komposisi masyarakat Kota Medan terdiri atas Melayu, Batak (Mandailing, Toba, Karo, Pakpak, Simalungun, Angkola), Jawa, Aceh, Minangkabau, Tionghoa, India (Tamil, Sikh). Komposisi masyarakat Kota Medan yang heterogen terbagibagi atas beberapa lokasi, hal ini disebabkan karena pada awalnya lokasi tersebut merupakan daerah awal tumbuh dan berkembangnya suku tersebut di Kota Medan. Perbedaan lokasi tersebut bukan merupakan gambaran penduduk yang terpecah-belah melainkan sebagai wujud persatuan etnisitas yang dimiliki setiap masyarakat di Kota Medan.

Medan merupakan kota metropolitan di provinsi Sumatera Utara yang didalamnya terdiri dari 21 Kecamatan. kesenian dikota medan mengalami perkembangan, terkhusus pada seni tari, keberadaan sanggar-sanggar di Kota Medan yang semakin banyak, diantaranya Patria, Citra Budaya, Nusindo, Elcis, Semenda, Lak-Lak,Tri Arga, Sinar Budaya Group, Sumatera Ethnic, Nusa Indah Entertaiment, Gold Entertaiment, $\quad M C D C, \quad \mathrm{Ai}-\mathrm{Ai}$ Dancer, dan lain sebagainya.

Tari media bakunya adalah gerak dan memiliki beberapa fungsi, adapun fungsi tari yaitu sebagai tari sebagai upacara, sebagai media ekspresi, sebagai media komunikasi, sebagai media apresiasi, tari sebagai pendidikan, salah satunya sebagai media berfikir kreatif, tari sebagai hiburan. Dimana lewat tari menyebabkan seseorang peka terhadap lingkungan, tanggap terhadap kejadian apapun, teliti, dapat menambahkan rasa ingin tau, dapat merangsang seseorang untuk 
menciptakan sesuatu yang baru lewat wawasannya.

Proses penciptaan tari bermula dari munculnya sebuah ide kreatif. Disini orang yang membuat atau menggarap sebuah karya tari disebut pencipta tari, penyusun tari atau koreografer. Seorang koreografer mempunyai kreativitas yang tinggi, kreativitas dalam tari adalah kemampuan seseorang untuk menghasilkan komposisi, prodak atau ide-ide baru yang sebelumnya tidak dikenal oleh penyusunnya sendiri. Untuk kemudian dilanjutkan dengan bereksplorasi gerak sesuai dengan ide garapan, Selanjutnya proses penciptaan tari berlanjut pada penambahan musik pengiring.

$$
\text { Banyaknya bermunculan }
$$

Sanggar- sanggar tari di Kota Medan tidak terlepas karena bidang ini dapat menghasilkan keuntungan yang bernilai materi, sehingga perubahan jasa menjadi nilai yang dapat di jual untuk mendapatkan keuntungan materi di sebut dengan Komodifikasi. Kemunculan ini terjadi karena adanya pengaruh dari globalisasi
Komodifikasi ini sangat
mempengaruhi dalam proses penciptaan, banyaknya permintaan pasar terhadap tari-tarian membuat koreografer terkadang kurang memperhatikan proses penciptaan, hanya berfokus pada penciptaan tari yang bersifat komersil, permintaan pasar yang banyak dan waktu yang tersedia cukup mendadak membuat karya tari yang dibuat bersifat instan sehingga tidak sempat lagi berfikir bagaimana yang seharusnya hasil karyanya bisa berfungsi sebagai media pendidikan, sebagai media apresiasi.

Tari yang bersifat komersil tidak hanya cukup dengan gerak-gerak tari yang di tampilkan, namun sangat memperhatikan penari-penari yang secara fisik bisa menarik perhatian, seperti tinggi badan, keidealan tubuh penari, cantik dan lain sebagainya. Walaupun kualitas gerak tidak memadai namun dengan ditunjang dengan penampilan para penari, maka itu bisa menjadi nilai jual di pasar. Disini penulis akan mengambil contoh sanggar tari yang ada di Kota Medan dan sesuai dengan topik yang di bahas yakni 
sanggar Ai-ai Dancer dan sanggar Nusindo dari keduanya memiliki jam terbang penampilan tari yang cukup banyak. Berdasarkan latarbelakang di atas maka penulis ingin mengkaji tentang pengaruh komodifikasi dalam penciptaan tari pada sanggarsanggar di Kota Medan.

\section{Landasan Teori}

Untuk membahas pengaruh komodifikasi dalam penciptaan tari pada sanggar-sanggar di kota medan penulis menggunakan teori komodifikasi dari Fairclough, teori penciptaan tari dari Hawkins, teori perkembangan untuk melihat kualitatif dan kuantitatif oleh E.B Harlock.

\section{Lokasi dan Waktu Penelitian}

Tempatdilaksanakannyapenel itianadalah di Sanggar-sanggar Kota Medan

\section{TeknikAnalisis Data}

Penulismenganalisadanmeng uraikan data-data tersebutdenganmenggunakanteknikk ualitatifyaitusebagaiprosedurpemeca hanmasalah yang diselidikidenganmenggambarkankea daaanobjekpenelitianpadasaatsekaran gKabupatenSimalungun.Waktu yang digunakandalampenelitianiniuntukm endapatkan data yang dibutuhkanadalahselamatigabulan yang akandilaksakanpadaOktober 2015 sampaiDesember 2015.

\section{PopulasidanSampel}

\section{Populasi}

populasidalampenelitianinibe rjumlahtiga orangyaitu sanggar tari di Kota medan, pelaku seni, event oranizer, wedding organizer.

\section{Sampel}

SampeldalampenelitianiniSan ggar Ai-aiDancer yang berada di KecamatanDenaidanSanggarNusindo yang berada di Kecamatan Medan Timur, narasumber.

\section{Teknik Pengumpulan Data}

Teknikpengumpulan data yang dilakukanadalahsebagaiberikut:

1. Studikepustakaan

2. Observasi 
3. Wawancara

4. Dokumentasi

\section{ISI}

Kota Medan memilikiluas 26.510

Hektar $(265,10 \mathrm{Km} 2$ ) atau 3,6\% darikeseluruhanwilayah Sumatera

Utara.Kota

Medan

memilikiluaswilayah yang

relatifkecil,

tetapidenganjumlahpenduduk yang relatifbesar.Secarageografis Kota Medan terletakpada $3^{\circ} 30^{\prime}-3^{\circ} 43^{\prime}$ Lintang Utara dan $98^{\circ} 35^{\prime}-98^{\circ} 44^{\prime}$ BujurTimur.

Etnis yang terdapat di Kota Medan cukupbanyak, diantaranyayakniMelayu, Batak Toba, BatakKaro, BatakSimalungun, Pak-pakDairi, Mandailing, Padang, Aceh, Tionghoa, India dansebagainya.

\section{A. Komodifiksai Pada Sanggar}

\section{Ai-ai Dancer}

Sanggar Ai-ai dancer berada di KecamatanMedanDenai, beralamatkan di jalan M.Nawi H.Komplekpemdablok K no 15 Medan Denai. pimpinansekaliguspelatih
aidancerbernamaTengku Ari Rahmana, S.Pd, namunbiasadipanggil Ai.Sanggar ini dapat menampilkan segala jenis pertunjukan tari, tari kreasi daerah, sexy dancer dan lain sebagainya. Pada sanggar Ai-aidancer, untuk memproduksisuatupertunjukantari, $\mathrm{Ai}$ sangatmemperhatikankualitaspenari

yakni memilkifisiktinggi yang proposional,memilkiwajah yang menarik(good looking), attitude selebriti, brain, beauty, and action.Lalu geraktaridankostum yang digunakanpadasaatpenampilan. Ini di karenakan penampilan penari sangat mempengaruhi permintaan pasar.

Cara pendistribusian pada sanggar ini dengan mengunggahfotofotokegiatan show menarimereka di media sosial (Medsos) seperti via $e$ mail, instagram, line, Path, Whats $U p, \quad B B M$, dansebagainya. Adapun pihak-pihak yang sering mengorder sanggar Ai-ai dancer yakni, instansi perusahaan, perorangan, wedding organizer dan event organizer.

\section{B. Komodifikasi Pada Sanggar Nusindo}

SanggarNusindoadalahsalahsat usanggar yang ada di Taman Budaya 
Sumatera Utara (TBSU). orang,

Sanggariniberdirisejaktahun 2001, selainitumetodepemasaranselanjutny padasanggarinibanyakterdapattari- ayaitudengancarapenyampaiandarim tarian yang ulutkemulut.

bersifathiburan.Irfansyahselakupelati Untukpihak-pihak yang hsekaligussangatmemperhatikankuali taspenari, geraktaridankostum yang digunakanpadasaatpenampilan.Seora ngpenarimenurutIrfansyahharuspand aimenari, displin, loyal, danSmart.Selainitu yang jugajadiprioritasutamauntuk yang perempuanharusmemilkitubuh yang ideal, putih, tinggi, berparascantik, berpenampilanmenari k.Hal inisangatmempengaruhipermintaanpa sar.UntukkostumtaripadasanggarNus indomemilkikostumsendiridan yang mendesainnyaadalahIrfansyahsendiri .Cara

\section{Penciptaan Tari Pada Sanggar Ai-ai Dancer} pendistribusiansanggarNusindo, berdasarkanpenjelasandaripimpinanIr fansyah, caranyadenganuploadfotodimediasos ial, sepertiInstagram, facebook, path, dan lain-lain, memberitahukankegiatanmenarimere kadimana, kapan, dantarianapa yang merekatarikan. inimenjadikegiatan yang praktisuntukdikenalolehbanyak

Sanggar Ai-ai dancer lebihbanyakmendapatkanjob yang bersifathiburanuntukkebutuhankomer sil, dalam proses penciptaannyatari yang sepertiinijikaadawaktu yang cukupsebelumwaktupertunjukanmak aAi selalumelakukan proses eksplorasi, Improvisasi, 
Gesture

danpembentukan. Kalaumendapatjob yang mendadakAi bisamenyelesaikantari yang di buatnyahanyamembutuhkan 1 kali pertemuandenganpenarinya, intensitaswaktunya 1,5 jam sampai 2 jam. Pernahjuga Aiaidancermendapatjob yang sangatmendadak, pada proses latihannyasiangharilalumalamnyalan gsungshow. Agar proses penciptaannyacepatAi mencaplokgerakandaritari yangsudahadalaludisusunsedemikian rupadenganmenyesuaikaniringanmus ik yang telahada. Gerakangerakannya di sesuaikandengankebutuhankonsumen .Pada proses pembuatannyabersifatinstan, jadisewaktuAi mencarigerakbeberapa kali delapanmakapenaridibelakangnyame ngikutinya agar langsungingatapa yang di buatolehnya. Untukjob sexy dancer

adalatihanmengeksplorgerakangerkan yang sexy danmenggoda.

\section{Penciptaan Tari Pada Sanggar Nusindo}

Berdasarkanhasilwawancaradeng anIrfansyahselakukoregrafer desember 2015) ,proses penciptaantariuntukkebutuhankomers ilbersifatinstan, karena sering medapatkan job secara mendadak. Dengantawaranjob yang banyak proses

pembuatannyaIrfansyahhanyamembu tuhkanwaktu 2 sampai 3 kali pertemuandenganpenari.Tarian yang diciptakantidakmemilikimakna, mengembangkandarigerak yang sudahada. Bahkanuntukmengejar target

menyiapkansuatutarianIrfansyahmen caplokdarisebagaiangerak-geraktari yang lain, kemudianditatasedemikianrupamengi kutimusik yang tepatmakaterciptalahtarian yang baru dan bentuk tari yang dipertunjukan juga disesuaikan dengan permintaan pasar.

\section{E. Kualitatif Dan Kuantitatif}

Dilihatdarisisikualitasnyasanggar Ai-aidancer sangatmemperhatikankualitasfisikpe 
nari,

karenaitumenjadidayatarikbagisangg

arnya.Setelahitupertunjukantariselalu

disesuaikandenganpermintaankonsu

men, terlebihlagisanggar Ai-aidancer

merupakansanggar

yang

dapatmenampilkansegalajenispertunj

ukantari.

Secarakuantitas,

padasanggar

Ai-aidancer

banyakmendapatkantawaranjob

untukpertunjukantari,

Hal

inimembuatkaryatari

yang

diciptakansudahsangatbanyakdan

proses penciptaannyabersifatinstan.

Sisi kualitas dari sanggar Nusindo dapat dilihat dari kualitas penari yang di pilih memang penari yang sudah berpengalaman,kemudian pemilihan fisik penari juga sangat selektif, kostum yang digunakan juga menggunakan kostum sendiri. Dalam seminggu Nusindo biasanya show 2 atau 3 kali. Pada beberapa kesempatan Nusindo menggunakan musik live untuk mengiringi tariannya. Seperti pada acara resepsi pernikahan di gedung Regale, ini menunjukkanwalaupun proses penciptaan tari pada sanggar Nusindo untuk kebutuhan komersil bersifat instan, namun sangat memperhatikan pengemasan pertunjukan tari tersebut dengan baik.

Dari sisi kuantitasnya dilihat dari jumlah tarian yang telah diciptakan pada sanggar ini sudah sangat banyak, kemudian tingginya jam terbang pertunjukan tari pada sanggar ini.

\section{PENUTUP}

Dari hasilpenelitian yang dilakukan di lapangandanpenjelesan yang

sudahdiuraikanmulaidarilatarbelakan ghinggapembahasan,

makadapatdisimpulkansecarakeselur uhanterhadappengaruhkomodifikasid alampenciptaanpadasanggar di Kota Medan sebagaiberikut:

1. Kesenianberkembangatauber ubahseiringdenganperubahan sosial.Kesenianterutamasenit ari pun merupakanhasilekspresijiwa yang tertuangdalambentukgerak yang melahirkankeindahan. Namunsemakinmajunyaind ustridanteknologi modern, 
kehidupanmanusiapunmengal amiperubahan. Begitu pula dengankesenianpadamasyara kat di Kota Medan mengalamiperubahanfungsi yang

dahulukentaldenganmagisdan religi, bernilaisenitingginamundeng anadanyaindustridankemajua nteknologiberubahsebagaihib uran komersil.

2. Komodifikasiadalahsemangat menciptakankeuntunganseban yak-

banyaknyamengakibatkanmu nculnyagejalakomodifikasidi berbagaisektorkehidupan.

Termasukpadasektorsenitari, saatinisenitari di kota Medan mengalamiperkembangan.

3. KarenapengaruhKomodifikas ipenciptaanpadasanggar Aiaidancer danNusindobersifatinstan, banyaknyapermintaantariden gantemaataukonsep yang berbeda-bedadarikonsumen. Membuatkoreograferpadaked uasanggariniseringmembuatk aryatarisehinggajumlahdarika ryataridarimasingmasingsanggarmenjadibanya $\mathrm{k}$.

\section{SARAN}

Dari

hasilkesimpulanpenelitian di atas, makadapat di ajukanbeberapa saran antara lain sebagaiberikut :

1. Penulisberharapadanyapenelit ianmasyarakatkotamedanuntu kmenjagamengembangkanser tamelestarikantari-tarian yang berada di kotamedan.

2. Diharapkanparakoreograferle bihmemperhatikankualitastari yandiciptakan.

3. Kedepannyasenitari di Kota Medan dapatberkembangdanmember ikanpengaruhpositifbagimasy araka 
Semoga penelitian ini dapat memberikan pengetahuan baru bagi masyarakat Simalungunbagaiman bentuk koreografi tari Simalungun
DAFTAR PUSTAKA

Ahmad, Ali Bachruddin\& Subandy, 2014 "Komunikasi \& Komodifikasi

Dkk, 2002. Metodologi Peneltian,

IAIN Sumatera Utara: Medan.

Fajardiane, Dwita. 2012. "Komodifikasi penggunaan jilbab sebagai gaya hidup dalam majalah muslimah". Universitas Sumatera Utara.

Hadi Y, Sumandiyo, 2007. Kajian Tari. Yogyakarta : Pustaka Book Publisher

Hawkins, Alma, 1964. Creating Through Dance. UCLA: Prentice Hall

Hawkins, Alma. Tanpa tahun. Moving form Within: A New Method for Dance Making. Bergerak Menurut Kata Hati. Terjemahan oleh I Wayan Dibya. Jakarta: MSPI, 2003.

Maryeni, 2005. Metode Penelitian Kebudayaan. Jakarta: Bumi Aksara

\footnotetext{
Nurwani ，2015. "Seni Dalam Perspektif Ilmu Sosial", Medan: Unimed Press
} 
Nurwani, 2014. "Bahan Ajar Pengetahuan Seni Tari”. Medan : Unimed Press

Purnamasari, Desi. 2014. Pengaruh Musik Sihutur Sanggul pada Penciptaan tari kreasi daerah batak toba di kota Medan, universitas Negeri Medan

Raharjo, Sumantri . 2011. Komodifikasi budaya lokal dalam televisi (Studi wacana kritis komodifikasi pangkur jenggleng TVRI Yogyakarta). Masters thesis, Universitas Sebelas Maret.

Royce, Anya PetersonTerjemahan F.X Widaryanto 2007.Anthropology Of Dance., Bandung : STSI Press

Sedyawati, Edi dan Soedarsono. 1986. "Pengetahuan Elementer Tari dan Beberapa Masalah Tari" Jakarta : Direktorat Kesenian Jakarta

Smith, Jacqueline Terjemahan Ben Soeharto. 1985. Komposisi Tari Sebuah Petunjuk Praktis. Yogyakarta : Ikalasti

Soedarsono, 1986, "Elemen-Elemen Dasar Komposisi Tari”, Yogyakarta : Laligo

Soedarsono, 2002, Seni Pertunjukan Indonesia di Era Globalisasi.
Yogyakarta: Gadjah Mada University press

Sudarwan, Danim, 2002. Menjadi peneliti Kualitatif, Bandung: CV. Pusta 